\title{
Triple Band Notch Loaded Hexagonal Patch Stacked Antenna
}

\author{
Chandrabhan ${ }^{1}$, Anil Kumar ${ }^{2}$ \\ Research Scholar ${ }^{1}$, Assistant Professor ${ }^{2}$ \\ Department of Electronics and Communication, SHUATS, Allahabad ${ }^{1,2}$ \\ cbhan.1965@gmail.com ${ }^{1}$ \\ anil.mera2002@gmail.com²
}

\begin{abstract}
The proposed antenna is a novel structure of stacked micro strip hexagonal patch antenna (SMHPA) operable in 2-6GHz range of frequency with resonant frequencies at $2.8 \mathrm{GHz}$ in sub-band 2.782.85GHz, 3.98GHz in second sub-band $3.88-4.08 \mathrm{GHz}$ and $5.78 \mathrm{GHz}$ in third sub-band $5.66-5.95 \mathrm{GHz}$ associated with high gains and sufficient return losses. The antenna can be used for WLAN, Wi-Max and mobile-communication. The proposed antenna has been simulated by High frequency structure simulation software (HFSS).
\end{abstract}

Key Words: SMHPA, WLAN, Wi-Max, Mobile Communication, HFSS

\section{INTRODUCTION}

A triple-band linearly polarized patch antenna as well as a dual-band dually polarized patch antenna with novel designs has been reported in previous years. A use of low-cost FR4 epoxy plate $\left(\varepsilon_{\mathrm{r}}=4.4, \tan \delta=0.02\right)$ with copper trace of $17 \mu \mathrm{m}$ thickness (rarely used) has been made for its design. Peak gains of 2.44, 2.12, and 1.64 $\mathrm{dBi}$ have been obtained at $2.24,2.36$, and $2.52 \mathrm{GHz}$, which are close to each other, respectively [1]. it was a latest observation in design of dual- or triple-band patch antenna by introducing U-slots in the patch of a broadband antenna, and the M-probe fed patch, the L-probe fed patch, aperture coupled stacked and coax-fed stacked patches, were also tested under the same methodology .In all these cases, authors used complex feed methods, multiple patches and more than one layer[2]. A dual-band, singly fed slotted microstrip antenna is used for wireless local area network (WLAN) at $2.4 \mathrm{GHz}$ and worldwide interoperability for microwave access (Wi-MAX) at 2.5/3.5 GHz. The antenna is comprised of an aperture-feeding method and a square patch with a narrow $\pi$-shaped slot to yield a dual-band resonance. The geometry is found to resonate at a lower frequency band ranging over 2.4-2.484 GHz for WLAN band and 2.5-2.69 GHz for Wi-MAX band. The higherfrequency resonance is obtained in the $3.5 \mathrm{GHz}$ Wi-MAX band. The antenna has a multilayered aperturecoupled feed configuration [3]. The multiband circular polarization (CP) is achieved by corner truncation, embedding slits and inclined slots on a three layered antenna structure. The antenna also shows wideband behavior with an impedance bandwidth of $52.13 \%$ in the frequency range of $4.85 \mathrm{GHz}$ to $8.27 \mathrm{GHz}$, while $3 \mathrm{~dB}$ axial ratio bandwidths in five CP bands are $0.51 \%, 4.54 \%, 0.33 \%, 0.83 \%$ and $1.29 \%$ in the frequency range of $5.12 \mathrm{GHz}$ to $5.15 \mathrm{GHz}, 5.45 \mathrm{GHz}$ to $5.70 \mathrm{GHz}, 5.90 \mathrm{GHz}$ to $5.92 \mathrm{GHz}, 6.25 \mathrm{GHz}$ to $6.31 \mathrm{GHz}$ and $7.68 \mathrm{GHz}$ to $7.78 \mathrm{GHz}$, respectively[4-6].In this proposed work, the microstrip patch antenna-1 and antenna-2resonate with impedance bandwidth of $2.5 \%$ and $2.3 \%$ at $2.8 \mathrm{GHz}, 5.0 \%$ and $7.8 \%$ at $3.98 \mathrm{GHz}, 5.0 \%$ and $4.89 \%$ at $5.78 \mathrm{GHz}$ and return losses at the same respective resonant frequencies stand at $-16.8 \mathrm{~dB}$ and $-18 \mathrm{~dB},-35.33 \mathrm{~dB}$ and $-22.8 \mathrm{~dB}$ and $-12.56 \mathrm{~dB}$ and-12.36dB.Comparative study of the antenna- 1 and antenna- 2 is prosecuted

\section{ANTENNA STRUCTURE}

Two antenna structures have been designed by two FR4-epoxy substrates of the same thickness of $1.6 \mathrm{~mm}$ stacked together without any gap with different dimensions and the ground is occupying the whole area underneath the lower substrate and the copper hexagonal patch of side $12 \mathrm{~mm}$ being centrally off oriented by $1 \mathrm{~mm}$ from the origin lies on the top of the upper substrate. Figure 1 and 2 exhibit all the dimensions and physical parameters according to given table1 for dimension of antenna-1 and the dimensions of the lower substrate along with ground in antenna-2 shown in figure 3 and 4 are reduced to equal to those of the upper substrate while keeping all the parameters same as those of antenna1. 
Table1. Dimensions for antenna1 and antenna2

\begin{tabular}{|c|c|}
\hline Specification & Dimension \\
\hline Substrate dielectric constant $\varepsilon_{\mathrm{r}}$ & 4.4 \\
\hline Loss tangent & 0.02 \\
\hline Length of substrate antenna1 L & $70 \mathrm{~mm}$ \\
\hline Width of substrate antenna1 W & $40 \mathrm{~mm}$ \\
\hline Height of substrates H=H1 & $1.6 \mathrm{~mm}$ \\
\hline Length of substrate antenna2 L1 & $28 \mathrm{~mm}$ \\
\hline width of substrate antenna2W1 & $28 \mathrm{~mm}$ \\
\hline Length of rectangular notch W3 & $10 \mathrm{~mm}$ \\
\hline Width of rectangular notch L3 & $0.5 \mathrm{~mm}$ \\
\hline Slot length L2 & $6 \mathrm{~m}$ \\
\hline Slot width W5 & $0.5 \mathrm{~mm}$ \\
\hline Slot height W4 & $1 \mathrm{~mm}$ \\
\hline Probe feed position (X1,Y1) & $(4,-8) \mathrm{mm}$ \\
\hline Shorting pin (X2,Y2) & $(-2,4) \mathrm{mm}$ \\
\hline Shorting pin radius & $0.67 \mathrm{~mm}$ \\
\hline
\end{tabular}

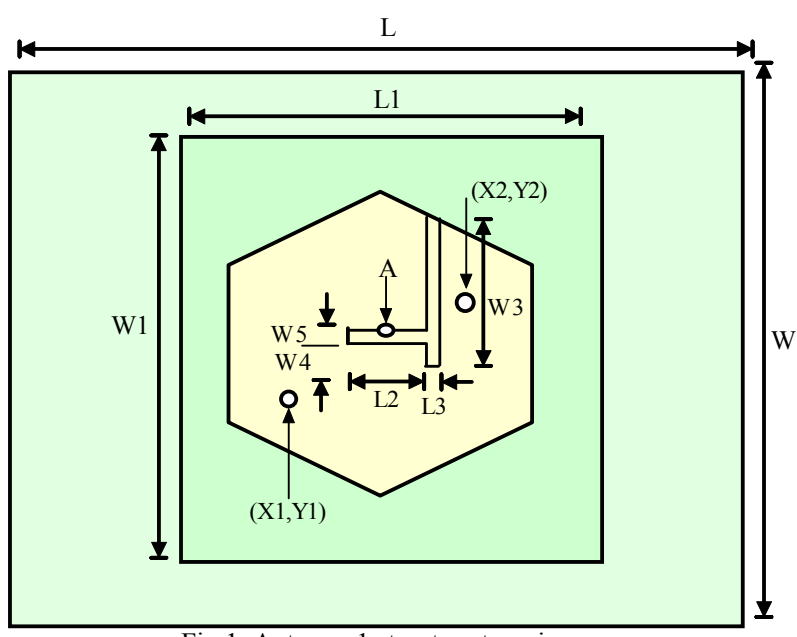

Fig.1. Antenna-1 structure top view

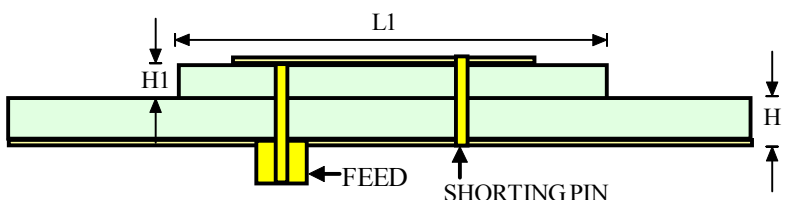

Fig.2. Antenna-1 structure side view

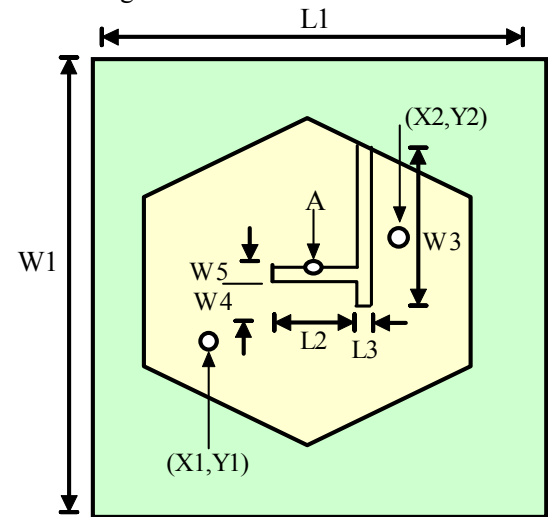

Fig.3. Antenna-2 structure top view

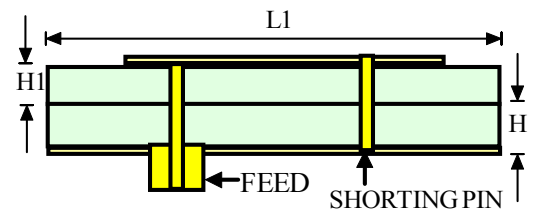

Fig.4. Antenna-2 structure side view 


\section{RESULTS AND DISCUSSION}

The return losses offered by the proposed antenna- 1 fall down to $-18.48 \mathrm{~dB}$ at $2.8 \mathrm{GHz},-38.32 \mathrm{~dB}$ at $3.98 \mathrm{GHz}$ and $-12.10 \mathrm{~dB}$ at $5.78 \mathrm{GHz}$ and the antenna -2 reaches on $-18 \mathrm{~dB},-22.8 \mathrm{~dB}$ and $-12.36 \mathrm{~dB}$ on the same consecutive resonant frequencies as shown in figure 5. The voltage standing wave ratios (VSWR) in figure 6are obtained at $1.47,1.22$ and 1.47 for antenna- 1 and for antenna-2, $1.23,1.09$ and 1.64 at $2.8 \mathrm{GHz}, 3.98 \mathrm{GHz}$ and $5.78 \mathrm{GHz}$, respectively.

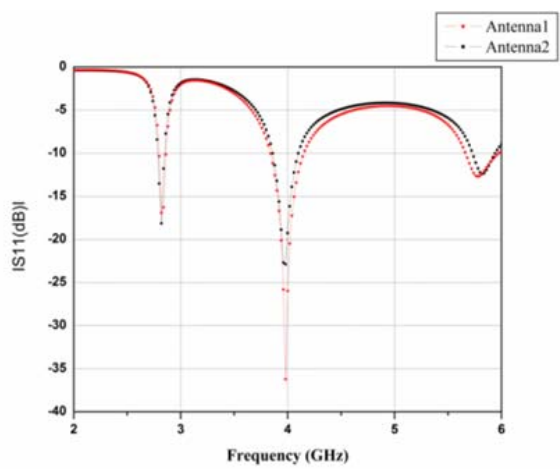

Fig.5.Returnlossversus Frequency of antenna1 and antenna2

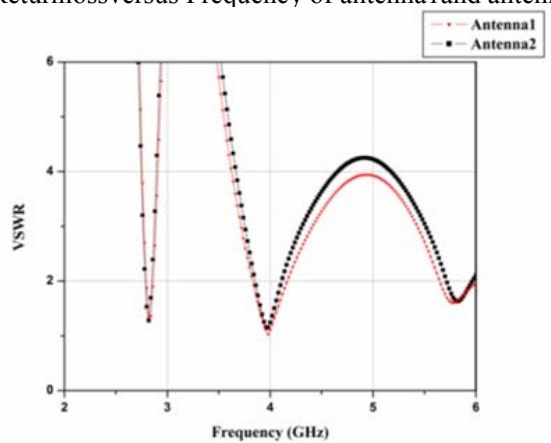

Fig.6. VSWR versus Frequency of Antanna1 and antenna2

Figure7 shows gains at resonant frequencies $2.8 \mathrm{GHz}, 3.98 \mathrm{GHZ}$ and $5.78 \mathrm{GHz}$ standing at the levels of $0.9 \mathrm{~dB}$, $5.8 \mathrm{~dB}$ and $1.9 \mathrm{~dB}$ for antennaland those of antenna 2 at $0.6 \mathrm{~dB}, 6.0 \mathrm{~dB}$ and 1.92 respectively.

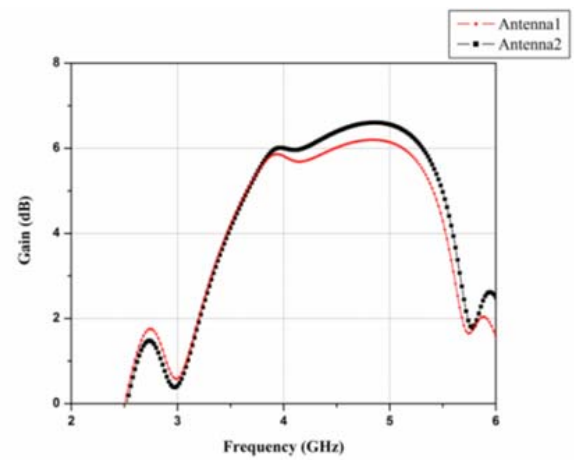

Fig.7. Gain Versus Frequency of antenna1 and antenna2.

The figure 8-13 exhibit the distribution of electric field in E-Plane $\left(\phi=0^{\circ}\right)$ and H-plane $\left(\phi=90^{\circ}\right)$. The radii at different Elevation angles $(\theta)$ of the circular scale represent the normalized magnitudes of the field in $\mathrm{dB}$ aligned along the $\theta=0^{\circ}$ radial axis representing $0.0 \mathrm{~dB}$ to $-40 \mathrm{~dB}$ field levels. The field pattern of antenna- 1 in figure 8 shows maximum radiation at bore side in E-plane whereas that in H-plane at an angle displaced $-30^{\circ}$ (left to bore side $\left(\theta=0^{\circ}\right)$ ) and the half power beam width (HPBW) of antenna-1 in E-plane is $98.86^{\circ}$ and that in $\mathrm{H}$-plane is $88.08^{\circ}$ at $2.8 \mathrm{GHz}$. Figure 9 for antenna-2 shows the maximum field along the bore side in both Eplane and $\mathrm{H}$-plane at $2.8 \mathrm{GHz}$ and the half power beam width (HPBW) in E-plane is $99.32^{\circ}$ and that in H-Plane is $93.45^{\circ}$ at $2.8 \mathrm{GHz}$. Figure 10 displays the field radiation patterns of antenna 1 with maximum strength along $+30^{\circ}$ (to the right of bore side) in E-plane and $-30^{\circ}$ (to the left of bore side) in H-plane and the half power beam 
widths in E-plane and H-plane are found to be $81.72^{\circ}$ and $77.2^{\circ}$, respectively at $3.98 \mathrm{GHz}$. Figure 11 for antenna-2 indicates maximum radiation at $0.43^{\circ}$ in both the planes and half power beam widths are obtained to be $83.06^{\circ}$ in E-plane and $77.19^{\circ}$ in H-Plane at $3.98 \mathrm{GHz}$. Figure 12 for antenna-1 at $5.78 \mathrm{GHz}$ shows the radiation pattern of maximum strength at $+30^{\circ}$ in E-plane and $-30^{\circ}$ in H-plane whereas the Half Power beam widths (HPBW) are $69.08^{\circ}$ and $92.09^{\circ}$ in E and H-Planes, respectively. Figure 13 for antenna-2 at 5.78GHz exhibits maximum strength at $31^{\circ}$ in both the planes and HPBWs are of $68.17^{\circ}$ and $64.97^{\circ}$ in E and H-planes, respectively.

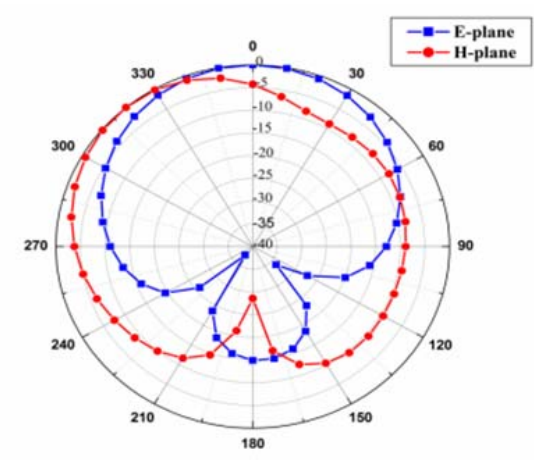

Fig.8.Radiation pattern of antenna1 at $2.8 \mathrm{GHz}$

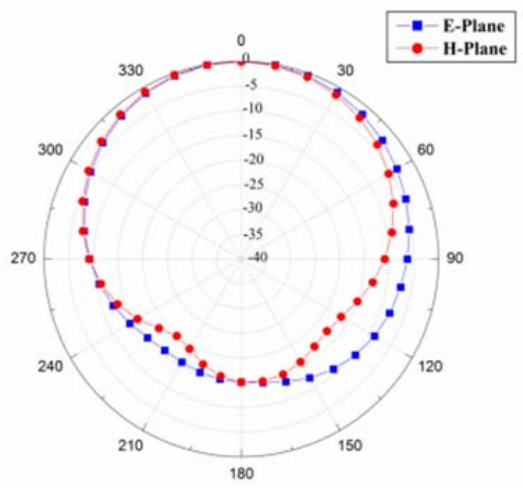

Fig.9.Radiation pattern of antenna 2 at $2.8 \mathrm{GHz}$

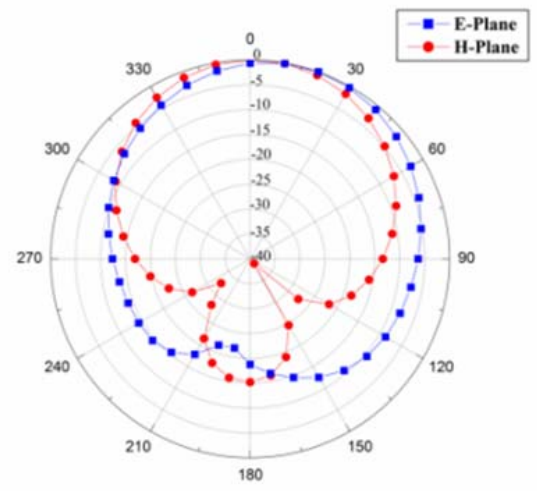

Fig.10.Radiation pattern of antenna1 at $3.98 \mathrm{GHz}$ 


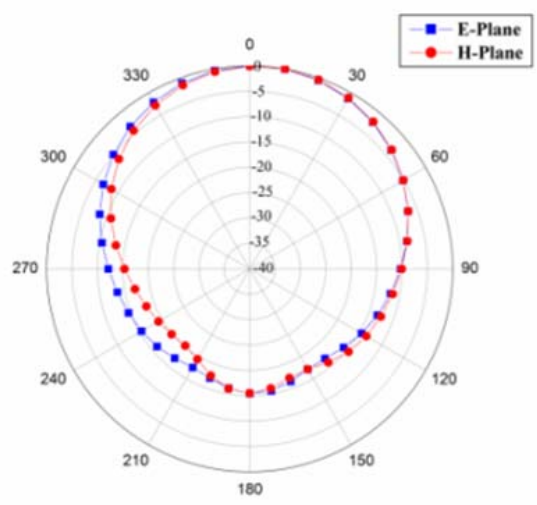

Fig.11.Radiation pattern of antenna2 at $3.98 \mathrm{GHz}$

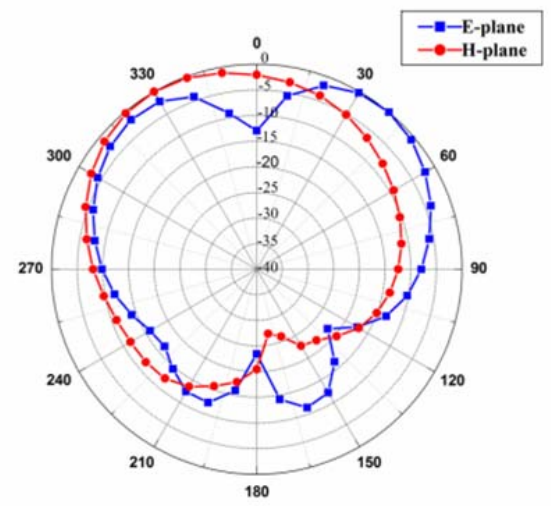

Fig.12.Field radiation pattern at $5.78 \mathrm{GHz}$ for antenna-1

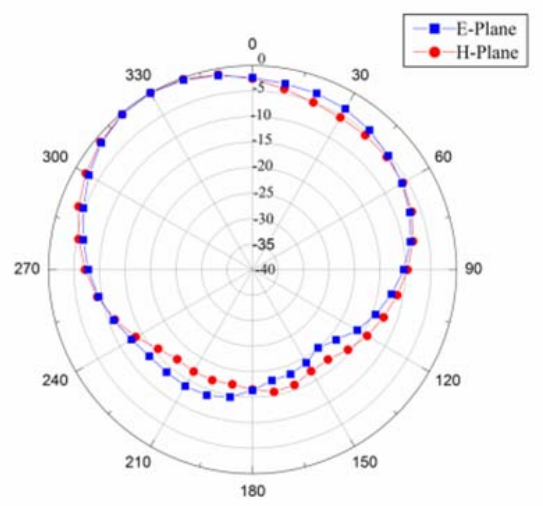

Fig.13.Field radiation pattern at $5.78 \mathrm{GHz}$ for antenna-2

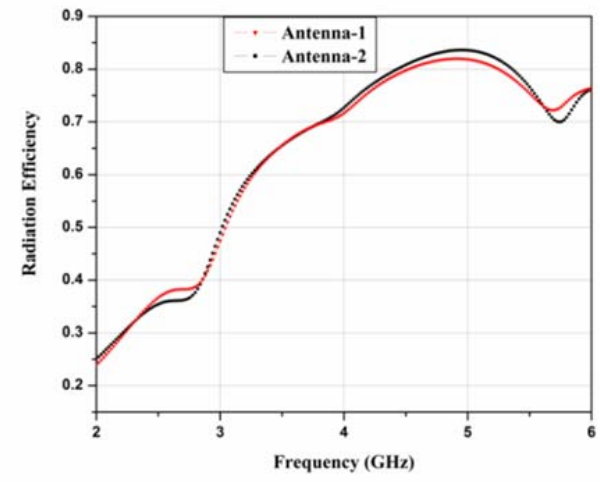

Fig.14. Radiation Efficiency Versus Frequency of antenna1 and antenna2. 
Figure-14 shows the comparison between the efficiencies of the antenna-1 and antenna-2. The efficiencies of antenna- 1 at $2.8 \mathrm{GHz}, 3.98 \mathrm{GHz}$ and $5.78 \mathrm{GHz}$ are $38 \%, 72 \%$ and $73 \%$ and antenna- 2 at the same frequencies provides $32 \%, 72 \%$ and $70 \%$

\section{CONCLUSION}

The put forth antenna in this paper finds its applicability in the field of wireless operation such as, WLAN, Wi-Max and mobile communication. The antenna can be operated at any point of frequency in the operating band $2.70-2.85 \mathrm{GHz}, 3.88-4.08 \mathrm{GHz}$ (S-band) and $5.66-5.95 \mathrm{GHz}$ (C-band). A vestige of C-band has been occupied by the second band of the antenna. With small sacrifice in return loss and the gain, some material can be saved.

\section{REFERENCES}

[1] Kushmanda Saurav, Debdeep Sarkar, and Kumar Vaibhav Srivastava "dual-Polarized Dual-Band Patch Antenna Loaded With Modified Mushroom Unit Cell” IEEE ANTENNAS AND WIRELESS PROPAGATION LETTERS, VOL. 13, 2014.

[2] Wing Chi Mok, Sai Hoi Wong, Kwai Man Luk, and Kai Fong Lee "Single-Layer Single-Patch Dual-Band and Triple-Band Patch Antennas" IEEE TRANSACTIONS ON ANTENNAS AND PROPAGATION, VOL. 61, NO. 8, AUGUST 2013.

[3] A.K. Sharma, A. Mittal and B.V.R. Reddy "Slot embedded dual-band patch antenna for WLAN and Wi-MAX applications" ELECTRONICS LETTERS 16th April 2015 Vol. 51 No. 8 pp. 608-609.

[4] Dinesh K. Singh, Binod K. Kanaujia, *, Santanu Dwari, Ganga P. Pandey, and Sandeep Kumar1, "Multiband Circularly Polarized Stacked Microstrip Antenna" Progress In Electromagnetics Research C, Vol. 56, 55-64, 2015.

[5] Abdullah A1 Noman Ovi1, Nandita Saha2, Shuvashis Dey2, and Nuzat Naury Alam2, Symmetrical Slot Loading in Elliptical Microstrip Patch Antennas Partially Filled with Mue Negative Metamaterials, PIERS Proceedings, Moscow, Russia, August 1923,pp.542-545, 2012.

[6] J. Ghalibafan and A. R. Attari, A NEW DUAL-BAND MICROSTRIP ANTENNA WITH U-SHAPED SLOT, Progress In Electromagnetics Research C, Vol. 12,pp 215-223, 2010. 